\title{
E-Serials: Publishers, libraries, users and standards
}

Edited by Wayne Jones. $2^{\text {nd }}$ ed. New York: Haworth Information Press, 2003. 294p. ISBN 07890 I 2294 (hbk), ISBN 0 789012308 (pbk)

This second edition retains most of the original chapters of the first, which was published in 1998; but the information has been brought up to date and new topics introduced. The editor acknowledges that there are bound to be gaps in the subject coverage, but to cover absolutely everything about electronic serials would produce a volume the size of a 'James Michener novel'. 
The book comprises 18 chapters which are grouped into a number of sections giving the reader a look at electronic serials from various points of view: publishing (2); pricing (I); acquisitions and collection development (4); cataloguing and metadata (3); preservation and archiving (I); projects and innovations (4); indexing (I); Uniform Resource Identifiers (I); and citation ( $\mathrm{I}$ ). Each has a different author - mainly librarians from academic institutions, or publishers. Most of the authors have addresses in the USA. Each chapter has its own bibliography, and the book is indexed.

A highlight of this book was the chapters in the section entitled "Acquisitions and Collection Development". Writing that it is "...an interesting time in which to be buying library materials" Ellen Finnie Duranceau (Digital Resources Acquisitions Librarian, MIT Libraries) sets the tone for a stimulating discussion in the first paragraph of her chapter, An eclipse of the sun: Acquisitions in the digital era where she lists some of the challenges facing acquisitions staff. "The issues acquisitions librarians face, the work they do, and the skills required to do it - all have shifted focus. We work in an environment with pricing models that require teams to analyze them, licenses that require legal expertise to evaluate and negotiate, and products whose massive, fluctuating content challenges our ability to provide information about what is being purchased and appropriate, accurate access from our catalogs. We work in an environment in which the very definitions of 'serial' and 'monograph' have become outdated at best, arbitrary at worst; an environment in which assumptions must be challenged and challenged again." The "sun" in Duranceau's title are the twin suns of the catalogue and traditional collection development methods. These, she maintains, are being realigned into new orbits around a new centre that has yet to be properly defined.

Using work flow diagrams to illustrate the acquisitions processes as followed at the Massachusetts Institute of Technology (MIT) Libraries, the author demonstrates that electronic serials cannot be treated exactly as their print counterparts. For electronic serials, the process is not linear and involves teams of staff instead of the individual at each step of the process for print serials. Because of the high costs involved in purchasing access to most electronic resources, the NERD Group (Networked Electronic Resources Discussion) at MIT Libraries compiled a decision matrix in order to rank the various criteria for purchase. The eleven ranked criteria that emerged from this exercise provide an essential tool to objectively assess resources. Once NERD has decided to purchase a resource, the digital resources librarian obtains a copy of the license and starts negotiating a price. Licenses are reviewed by another team. Communication is also required with the Information Systems office to discuss access methods. After a trial period and when negotiations are concluded, NERD will make the final purchase decision.

A section in this chapter deals with licensing issues - a topic that strikes fear into most librarians. Many standard licenses are now freely available for use, along with general licensing principles. The chapter points out key licensing issues which all purchasers must consider: who, how, where and what - "the definition of the user population, how the product can be used, where the product can be used, and what is being purchased."

In a chapter entitled Collection Development for Online Serials Redux: Now who needs to do what, why and when, Mark Jacobs and Cindy Stewart Kaag (both librarians at Washington State University) provide several pages of guidelines for selecting, processing and accessing electronic resources. Although it is important to set up a process for dealing with electronic serials, it is equally important to remember that things can change very quickly, and that once the process is in place it may need to be adapted. They caution that the addition of electronic serials to a library collection can be overwhelming for library staff and users. The newness of the approach and the changes involved may be intimidating. It is important to try to prevent panic by instilling the realisation in everyone that, basically, the library's purpose remains unchanged; it is just that the method in which the material is sent to the user that is different.

In the last chapter in this section, Kristin H. Gerhard (Electronic Resources Coordinator and Catalogue Librarian at lowa State University) focuses on the model for electronic resources management as adopted by lowa State University. Electronic resource management crosses departmental and divisional lines, and lowa State therefore created the position of coordinator. This post is located within the Acquisitions Department, in technical services. The advantages to this approach are: (i) The coordinator acts as a funnel and collection point for information from all sources; (ii) It is important to have a single contact person to whom staff can bring complex questions, issues and concerns; (iii) The coordinator is responsible for the flow of information regarding electronic resources across departmental and divisional lines. There are also potential pitfalls: (a) There is no single person to provide backup to the electronic resources coordinator; (b) The position requires constant communication among a wide variety of people.

Steven C. Shadle (Serials Cataloguer, University of Washington Libraries) and Jim Cole (Principal Serials Cataloguer, lowa State University Library) each write a chapter on the problems of applying the standards (AACR2 and ISBD), that worked well in the print monograph world, to the electronic environment.

Within the other sections of the book there are chapters devoted to the development of ScienceDirect, Serials Solutions, D-Lib Magazine, and D Space.

For anyone working with electronic resources, this is a wonderful book full of thought-provoking writings. 
Caroline E Dean, Electronic Resources Librarian, University of Cape Town Libraries, South Africa Tel.: +27(21) 6503701

e-mail:caroline@uctlib.uct.ac.za 